\title{
Multiple Sclerosis incidence rate in southern Iran: A Bayesian epidemiological study
}

\section{Naeimehossadat Asmarian}

Shiraz University of Medical Sciences

\section{Zahra Sharafi ( $\square$ zahra10926@gmail.com )}

Zahedan University of Medical Sciences

\section{Amin Mousavi}

University of Saskatchewan

\section{Reis Jacques}

Changhai Hospital

\section{Ibon Tamayo}

Harvard University

\section{Marie-Abèle Bind}

Harvard University

\section{Marzie abutorabi-zarchi}

Shahid Sadoughi University of Medical Sciences and Health Services

Mohammad Javad Moradian

Shiraz University of Medical Sciences

\section{Research article}

Keywords: Bayesian spatio-temporal model, Multiple sclerosis, Incidence rate

Posted Date: June 16th, 2020

DOI: https://doi.org/10.21203/rs.3.rs-34188/v1

License: (c) (1) This work is licensed under a Creative Commons Attribution 4.0 International License.

Read Full License

Version of Record: A version of this preprint was published at BMC Neurology on August 10th, 2021. See the published version at https://doi.org/10.1186/s12883-021-02342-1. 


\section{Abstract}

Background: Multiple Sclerosis (MS) remains to be a public health challenge, due to its unknown biological mechanism and clinical impact on young people. The prevalence of this disease in Iran is reported to be 5.3 to 74.28 per 100000 cases. Due to high prevalence of this disease in Fars province, this study aimed to assess the distribution of MS in this region in southern Iran by evaluating its covariates.

Method: Data from 5,468 patients diagnosed with MS were collected, according to the McDonald's criteria, which was reported by the MS Society of Fars from 1991 until 2016. Bayesian spatio-temporal models was also used to describe MS incidence in Fars province. We also investigated the association between overall MS incidence rate and the overall percentage of vitamin D intake, smokers in the population as well as the overall percentage of people with normal BMI as well as alcohol consumption in a population from 1991 until 2016 by Besag, York and Mollie's (BYM) model.

Results: County-level crude incidence rates ranged from 0.22 to 11.31 cases per 100,000 population. The highest relative risk was estimated at 1.8 in the city of Shiraz, the capital of Fars province while the lowest relative risk was estimated at 0.11 in Zarindasht County in southern Fars. The percentages of vitamin D3 intake was significantly associated with the incidence of MS. Although $1 \%$ increase in Vitamin D3 intake is associated with $2 \%$ decrease in the risk of MS, $1 \%$ increase in smoking is associated with $16 \%$ increase in the risk of MS, respectively.

Conclusion: Spatial analysis of MS showed low incidence rate of this disease in the south and south east of Fars province, which is due to the effect of different covariates. As suggested by previous studies, vitamin $\mathrm{D}$ and smoking among all covaiates might be associated with high incidence of MS.

\section{Background}

MS is an autoimmune disorder, in which the central nervous system myelin is attacked. It results in focal lesions and clinical symptoms [1, 2]. In other words, it is a common neurodegenerative inflammatory disease, resulting from myelin and axonal degeneration, predominantly in young adults [1]. The disease is classified into four different courses: a) Relapsing-Remitting (RR) MS, the most common type, which include $85-90 \%$ of all cases; b) Secondary Progressive (SP); c) Primary Progressive (PP) MS, accounts for only $10 \%$ of the cases; and d) Progressive Relapsing (PR) MS [3]. Worldwide, more than 2.3 million individuals affected by these different type MS [4-6]. The distribution of MS increases retrospectively with distance from the Equator. For example, Canada, Norway, and Sweden have some of the highest prevalence rates of MS in the world, reported in 2013. However, there are exceptions; some countries further away from the equator, such as Russia have low prevalence, whereas other countries closer to the equator, for instance Australia, show a high prevalence [5,6]. Epidemiological studies based on the geographical region shows that the prevalence ranged from 5.3 to 74.28 per 100,000 individuals in Iran, which is not evenly distributed across different regions [7]. Fars province with 72.1/100,000 (116.5 in 
females and 28.3 in males) prevalence rate in 2013 is one of the high risk provinces for this disease. The mean annual incidence rate was 5.2/100,000 from 2002 until 2012 [8].

Environmental risk or lifestyle factors including vitamin D deficiency, obesity, alcohol consumption, and cigarette smoking have been identified. Both low vitamin D levels and cigarette smoking are the strongest risk factors $[5,6,9,10]$. Although many studies that have investigated the epidemiology of MS and examined the effect of different genetic, environmental and lifestyle factors on this disease [2, 6, 11-21], to the best of our knowledge, there is no study, which has estimated the Spatio-temporal incidence rate of MS in Fars province. Spatio-temporal modeling allows the health outcomes, both in space and time to be simultaneously evolve [22].

This study models the incidence of MS in Fars province in southern Iran over a 26-year period between 1991 to 2016 . We also simultaneously investigate the effects of some covariates such as 1) vitamin D3, 2) smoking, 3) BMI, 4) alcohol consumption on the number of multiple sclerosis in 29 Fars province counties, using Besag, York and Mollie's (BYM) spatial-temporal models.

\section{Methods}

\section{Study area}

Fars province is located in the southwest region of Iran (Figure 1 left) and covers $120,608 \mathrm{~km}^{2}$ of land. The province is subdivided into 29 counties and has 4.8 million inhabitants ( $51 \%$ males) according to 2016 census report by the Statistical Center of Iran (SCI)[23]. According to census, Fars population in 1996 was $3,817,036(1,927,415$ males and $1,889,621$ females), in 2006 was $4,336,878$ (2,204,852 males and 2,132,026 females), and in 2016 it reached 4,851,274 (2,461,251 males and 2,390,023 females). To average out, we used 2006 population to estimate the relative risks. The population at risk (i.e. scaled 1/100,000) in 2006 for the 29 counties is shown in Figure 1 (right). As shown in the left figure 1, Shiraz has the highest population at risk.

\section{Data}

This is a historical and retrospective cohort study, carried out in MS Society of Fars province from 1991 until 2016. This center is the only MS registry center in Fars province, so the information of almost all MS patients is available in its database. All MS patients who fulfilled the McDonald's criteria [24] from 1991 to 2016 were included in this study. Suspicious cases were referred to the MS committee of Shiraz University of Medical Sciences (SUMS) to a neurologist and were again reevaluated by three expert neurologists to confirm their diagnosis. We excluded all patients from other neighboring provinces that were registered in this longitudinal database. Data of covariates, such as the overall percentage of vitamin D intake, smoking in the population as well as the overall percentage of people with normal BMI and alcohol consumption in the population within the period of 1991-2016 were extracted from the annual health census from the Ministry of Health and medical Education in Fars province, available in SUMS database. 


\section{Statistical analysis}

In this study, the geographical variation of MS incidence in 29 counties was analyzed. Standardized Incidence Ratio (SIR) was calculated for each county, using the direct method. For the assessment of potential effect of the risk factors on relative risks, data were analyzed, using BYM model, suggested by Besag, York and Mollie's (1991). We applied spatiotemporal model (adapted of BYM model for spacetime problems) presented by Bernardinelli et al. (1995) to identify the temporal pattern of MS disease.

The BYM model is one of the most popular full Bayesian models, which is explained in many references with detail (see Blangiardo M, Cameletti M. Spatial and spatio-temporal Bayesian models with R-INLA. John Wiley \& Sons; 2015 Jun 2. Page 231). We considered Vitamin D3 intake, smoking, normal BMI, and alcohol consumption as risk factors. The observed number of MS in a geographic unit (county) was assumed to follow a Poisson distribution. In the Bayesian structure, the intercept and fix effects was assumed to follow an improper uniform and normal distribution with zero mean and a small variance as prior. The precision parameters, which control the amount of variability for the random effects, were assumed to follow a gamma distribution $(0.5,0.0005)$, as suggested by Bernardinelli et al.,1995 (Lawson et al., 2003).OpenBUGS version 3.2.3 [25]was used to estimate parameters and ArcGIS 10.1 [26]was used to display them on maps. We ran two chains with 1000 samples as burn-in and 10000 samples as iteration. Convergence for the chains were confirmed, and the differences between the two chains were very small [27].

\section{Results}

We identified 5,468 new MS cases 4344 (79\%) women and 1124 (21\%) men in Fars province from 1991 to 2016 . A total of 3664 patients $(67 \%)$ were from the city of Shiraz, the capital of Fars province.

Table 1 shows the number of new MS cases in each year, incidence rate per 100,000 population, age, and number of female and male in each year in Fars province during the mentioned 26 years. The highest and lowest incidence rates were observed in 2014 as $11.31(95 \% \mathrm{Cl}(10.39,12.30)$ per 100,000) and 1992 as $0.22(95 \% \mathrm{Cl}(0.11,0.44)$ per 100,000). In addition, the highest and lowest age mean were observed in $2014(32.11 \pm 9.40)$ and $1993(25.12 \pm 8.73)$. The highest and lowest female/male ratio were observed in 2006 (5.86) and 1991(1.44).

Table 1. Incidence of MS per 100,000 persons in the county levels of Fars province in the south of Iran from 1991 to 2016 
Year No. of cases
Incidence rate

$(95 \% \mathrm{Cl})$
Age at diagnosis (y)

$\begin{array}{ll}\text { Mean } \pm S D & \text { Min- } \\ & \max \end{array}$

$\begin{array}{ll}\text { Mean } \pm S D & \text { Min- } \\ & \max \end{array}$

$1991 \quad 22$

$0.61(0.40,0.93)$

$0.22(0.11,0.44)$

$0.86(0.61,1.22)$

$0.75(0.52,1.08)$

$1994 \quad 28$

$1995 \quad 35$

$0.92(0.66,1.28)$

$0.91(0.65,1.27)$

$0.67(0.45,0.98)$

$1997 \quad 26$

$1998 \quad 48$

$1.22(0.92,1.61)$

$1.93(1.54,2.41)$

$1999 \quad 77$

$2000 \quad 77 \quad 1.90(1.52,2.38)$

200191

$2002 \quad 104$

2.22(1.81,2.73)

$2.51(2.07,3.04)$

$2.83(2.37,3.39)$

$3.13(2.64,3.71)$

$2004 \quad 133$

$2005 \quad 199$

$2006 \quad 199$

$2007 \quad 228$

$2008 \quad 279$

$2009 \quad 288$

45)

$\begin{array}{ll}26.89 \pm 8.25 & (11- \\ & 43)\end{array}$

$\begin{array}{ll}27.43 \pm 8.28 & (12- \\ & 46)\end{array}$

$25.24 \pm 5.89$

(14-

40)

$31.51 \pm 12.8 \quad(13$

$28.21 \pm 8.43 \quad(14$
$48)$

$29.44 \pm 8.77 \quad(9-48)$

$28.01 \pm 8.50$

(8-55)

$28.20 \pm 8.42$

(14-

53)

$2003 \quad 119$

$29.09 \pm 9.03$

(11

56)

$28.58 \pm 8.46$

(10-

59)

$28.57 \pm 8.06$

(13-

53)

$\begin{array}{lll}4.57(3.98,5.26) & 28.82 \pm 8.62 \quad(12- \\ & & 59)\end{array}$

$\begin{array}{lll}4.57(3.98,5.26) & 28.82 \pm 8.62 & (12- \\ & & 59)\end{array}$

$31.23 \pm 10.80$

$5.18(4.55,5.90)$

$30.09 \pm 8.98$

$6.27(5.58,7.05)$

$30.47 \pm 9.01$

$(10$
No. of cases

Female/male
F/M ratio

$28.45 \pm 8.11 \quad(10-\quad 13 / 9$

1.44

(22- $\quad 6 / 2$

3

$\begin{array}{lll}30.30 \pm 8.08 & (22- & 6 / 2 \\ 44) & \end{array}$

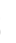

1.91

$25.12 \pm 8.73 \quad(8-44) \quad 21 / 11$

1.80

$18 / 10$

$\begin{array}{lll}27.32 \pm 8.09 & \left(\begin{array}{ll}16- \\ 46)\end{array}\right. & 29 / 6\end{array}$

4.83

$31 / 4$

7.75

4.20

$21 / 5$

(13- $\quad 39 / 9$

4.33

(14- $\quad 59 / 18$

3.28

$62 / 15$

4.13

$77 / 14$

5.50

$101 / 32$

3.16

$169 / 30$

5.63

$170 / 29$

5.86

4.78

8.15

(7-86) 186/42

4.43

(9-55) 221/58

3.81

56)

4.65 


\begin{tabular}{lllllll}
2010 & 391 & $8.59(7.78,9.49)$ & $29.77 \pm 8.64$ & $(8-63)$ & $323 / 68$ & 4.75 \\
\hline 2011 & 438 & $9.52(8.67,10.46)$ & $31.49 \pm 9.45$ & $(5-69)$ & $366 / 72$ & 5.08 \\
\hline 2012 & 488 & $10.49(9.60,11.47)$ & $30.26 \pm 8.84$ & $(7-64)$ & $405 / 83$ & 4.88 \\
\hline 2013 & 510 & $10.85(9.95,11.83)$ & $30.80 \pm 9.08$ & $(9-60)$ & $397 / 113$ & 3.51 \\
\hline 2014 & 537 & $11.31(10.39,12.30)$ & $32.11 \pm 9.40$ & $(11-$ & $432 / 105$ & 4.11 \\
\hline 2015 & 533 & $11.10(10.20,12.09)$ & $32.09 \pm 9.27$ & $(8-62)$ & $415 / 118$ & 3.52 \\
\hline 2016 & 543 & $11.20(10.29,12.18)$ & $32.43 \pm 8.82$ & $\begin{array}{l}(11- \\
62)\end{array}$ & $354 / 189$ & 1.87
\end{tabular}

Age-specific prevalence rates of MS are shown in Table2. The highest and lowest prevalence rates belonged to $30-40(26.01(95 \% \mathrm{Cl},(24.8,27.3)$ per 1,000,000) and <20 (95\% Cl, $4.31(4.00,4.64)$ per $1,000,000)$ age groups. A statistically significant difference was determined between the prevalence of MS amongst men and women $(P<0.0001)$, except age group $>60$. Highest and lowest values of MS ratio of women to men were observed in $<20(4.65)$ and $>60$ (1.5) age groups.

\section{Table 2. Age-specific prevalence rates of MS in the county (per 1,000,000 persons) of Fars province in the south of Iran from 1991 to 2016}

\begin{tabular}{llllll}
$\begin{array}{l}\text { Age } \\
\text { group }\end{array}$ & $\begin{array}{l}\text { No. of } \\
\text { cases }\end{array}$ & Prevalence & $\begin{array}{l}\text { No. of cases } \\
\text { Female/male }\end{array}$ & $\begin{array}{l}\text { F/M } \\
\text { ratio }\end{array}$ & $\begin{array}{l}\text { P-value F to } \\
\text { M }\end{array}$ \\
\hline$<20$ & 689 & $4.31(4.00,4.64)$ & $567 / 122$ & 4.65 & $<0.0001$ \\
\hline $20-30$ & 2261 & $21.71(20.83,22.63)$ & $1797 / 464$ & 3.87 & $<0.0001$ \\
\hline $30-40$ & 1629 & $26.01(24.8,27.3)$ & $1301 / 328$ & 3.97 & $<0.0001$ \\
\hline $40-50$ & 742 & $15.89(14.79,17.08)$ & $565 / 177$ & 3.19 & $<0.0001$ \\
\hline $50-60$ & 132 & $4.54(3.83,5.39)$ & $105 / 27$ & 3.89 & $<0.0001$ \\
\hline$>60$ & 15 & $4.92(2.96,8.15)$ & $9 / 6$ & 1.5 & 0.6056
\end{tabular}

We generated maps of geographical variations of MS incidence across the 29 counties of Fars province with classic SIR (Fig. 2A), BYM model (Fig. 2B) spatiotemporal model (Fig. 2C), and posterior estimate value of (Figure 2D). shows the difference between the global trend and the area-specific trend, showing that this trend is less steep than the mean trend, whilst shows that the area-specific trend is steeper than the mean trend. The maps should be interpreted by considering that different shades are proportional to the incidence rate value. In other words, the darker the area, the higher the incidence of 
MS. The averages of SIRs and relative risks were 0.52 and 0.43 , respectively. As can be seen in Figure 2 (A and B), Shiraz is at higher risk than other counties. Shiraz had the highest SIR and relative risk for MS with values of 1.8 and 1.8 (standard deviation=0.03), respectively. Zarindasht county in southeast of Fars province had the lowest SIR and relative risk, with values of 0.06 and 0.11 (standard deviation= 0.03 ), respectively. Figure $2 \mathrm{C}$ shows the temporal trend of the incidence rate across different regions of Fars province during the period of 1991-2016. The estimated value of time coefficient in this model was 0.0075. The exponential corresponding to the coefficient of time is equal to 1.007 for each successive year. This finding shows that although there is an increasing trend of incidence in Fars, it is very uniform. Figure 2D shows the change of temporal patterns of MS incidence rate. Darker areas show that the trend is steeper for those counties compared with the global trend and brighter areas show that the trend is less steep than the global trend.

Another important point that can be inferred from Figure 2C, is the steady increase of incidence rate of relative risk over time in the northern regions of the province. Figure $2 \mathrm{~B}$ depicts the average over a period of 26 years, showing higher overall incidence rates in the central regions of Fars. On the other hand, Figure $2 \mathrm{C}$ incorporates relative changes over this time period, showing a geographical shift of the incidence rate from the central regions to the northern regions of the province.

\section{Table 3. Summary statistics: posterior mean, posterior standard deviation (SD) and posterior $95 \%$ credibility interval for the fixed effects of BYM models in MS incidence}

\begin{tabular}{llll} 
Covariate & Coefficient (SD) & Exp (coefficient) & 95\% Confidence Interval \\
\hline \% of Vitamin D3 intake & $-0.022(0.005)$ & 0.978 & $(-.022,-0.008)^{\star}$ \\
\hline \% of smoking & $0.149(0.065)$ & 1.161 & $(0.032,0.240)^{\star}$ \\
\hline \% of normal BMI & $0.021(0.023)$ & 1.021 & $(-0.020,0.022)$ \\
\hline \% of Alcohol consumption & $1.012(0.777)$ & 2.750 & $(-0.511,2.585)$
\end{tabular}

Table 3 is a summary of the statistics related to different covariates used in BYM model. The fixed effects estimated are presented in Table 3 which shows that the percentages of vitamin D3 intake are significantly associated with MS incidence. Although 1\% increase in Vitamin D3 intake is associated with $2 \%$ decrease in the risk of MS incidence, $1 \%$ increase in smoking is associated with $16 \%$ increase in the risk of MS incidence.

\section{Discussion And Conclusion}

This study spatially evaluated the MS incidence distribution in Fars province, using Bayesian model. Spatial description of the disease is a useful tool for evaluating the incidence rate data and to generate leads in further public health investigations and interventions [28]. As far as we know, this is the first 
study to have estimated the Spatio-temporal incidence rate of MS. This study also investigates the association of vitamin D3, smoking, BMI, and alcohol consumption with MS incidence rate, as well as spatial dependence between the neighboring regions. The findings suggest that further studies are warranted in order to confirm the allocations of health resource across different region.

The results of BYM model describes the low incidence rate of MS in south and southeast of the province. Zarindasht county, located in south with hot and dry climate and high temperature, had the lowest incidence rate. This result is in line with previous studies that showed maintaining adequate levels of vitamin $D$ (as one of the environmental factors) have a protective effect, resulting in lower risk of developing autoimmune diseases including MS[29-31]. The results of this study also showed that larger cities, located in the center of province, especially Shiraz and Abadea in northeast had high MS incidence rates. This is in concordance with previous studies which showed MS to be more common among urban dwellers than rural ones[32]. There is no clear explanation as to why, but higher frequencies in these regions might be due to more accurate diagnosis in these regions which is a result of easier access to healthcare and higher-quality diagnostic procedures. Although, high socioeconomic status (SES) index which includes income, education, ethnicity, job and asset is generally associated with better health outcomes, it seemed that regions with higher SES (i.e. urban areas compared to rural areas) had led to increased risk of MS. However, this is just an association and not a cause, but the reason is unknown [32, 33]. Even though some previous studies were in line with our result, some were contrary and reported no evidence of an association between MS incidence and SES or reported an association with low SES [3234].

Our results showed that the percentage of Vitamin D3 intake and smoking can be associated with reduced risk of MS incidence, which is in line with previous studies that had suggested maintaining adequate levels of vitamin $D$ can have a protective effect by lowering the risk of developing autoimmune diseases including MS[29-31]. When a person has MS, his or her immune system attacks the coating that protects nerve cells. Research suggests a significant positive effect of vitamin $D$ on the immune system. [29-31, 35]. Smoking as a risk factor can influence the course of MS [16, 36, 37]. Both duration and smoking intensity can contributed independently to the increased risk of MS [38]. Studies amongst MS patients and healthy controls, consistently have provided evidence that both active and passive smoking can result in an increased risk of MS and disease progression. Studies have shown that the risk of MS associated with HLA genotypes is increased by smoking status $[36,39]$.

According to several studies, obesity is one of the potential risk factors of MS. The growing world-wide obesity epidemic has multiple deleterious effects on public health and has also been associated with an increased risk of MS [40]. Increased obesity leads to lower levels of 25-hydroxyvitamin D, which in turn predisposes to MS [41]. The association between obesity and MS is similar amongst men and women, and the observed trend of higher BMI resulted in a higher risk of developing MS [42]. However, in our study BMI was not associated with the incidence of MS. 
Although the impact of alcohol, which might directly suppress various immune responses, on the risk of developing MS has been investigated in different studies, the results were inconsistent. In some studies, researchers found no association between alcohol intake and risk of MS [43], but in some other researchers showed a potential dependency between alcohol consumption and the incidence of MS [10].

Our study had some limitations, which should be taken into consideration in future studies. The major limitation of the present study was that although the MS incidence rate was longitudinal, covariate information was not available per year between 1991 and 2016; hence, we had the overall information of these covariates during this period. Lack of this information prevented us from using these covariates in spatio-temporal model, but investigated their effect on longitudinal mapping. Another limitation was that in this study we focused only on the statistical test results while assessing the effect size gives additional information about the extent of the effected values. Since the incidence and prevalence rates are different in male and female [20], further investigations on the impact of other important covariates, such as climate, sunlight, and air pollution should be conducted [13, 17, 44-48].

Conclusion: Spatial analysis of MS showed low incidence rate of this disease in the south and south-east of Fars province. In addition, large cities also had very high MS incidence rate. Effect of different covariates which were investigated in this study showed that vitamin $D$ and smoking among all covaiates might be associated with the incidence of MS.

\section{Declarations}

\section{ETHICS APPROVAL AND CONSENT TO PARTICIPATE}

All procedures performed in studies involving human participants were approved by the ethics committee and in accordance with the ethical standards of the Shiraz University of medical science. Written consent was originally obtained by the MS Society of Fars province from participants.

\section{Consent for publication}

Not applicable

\section{Availability of data and materials}

The datasets are available from the corresponding author on reasonable request.

\section{Competing interests}

The authors declare that they have no competing interests.

\section{Funding}

This research received no specific grant from any funding agency in the public, commercial or not-forprofit sectors. 


\section{AUTHORS' CONTRIBUTIONS}

NSA and ZSH: designed the study, performed the statistical analyses and interpretation and wrote the manuscript, AM: interpret statistical analysis and wrote the manuscript. RJ, IT, MAB, MA and MJ M: were consulted on the design of the study and reviewed the draft. All authors read and approved the final manuscript.

Acknowledgment: The authors are grateful from Fars Multiple Sclerosis Society affiliated with Shiraz University of Medical Sciences for providing data and information. Also, the authors wish to thank Mr. $\mathrm{H}$. Argasi at the Research Consultation Center (RCC) of Shiraz University of Medical Sciences for his invaluable assistance in editing this manuscript.

\section{References}

1. Gourraud PA, Harbo HF, Hauser SL, Baranzini SE: The genetics of multiple sclerosis: an up-to-date review. Immunological reviews 2012, 248(1):87-103.

2. Dyment DA, Ebers GC, Sadovnick AD: Genetics of multiple sclerosis. The Lancet Neurology 2004, 3(2):104-110.

3. Lublin FD, Reingold SC, Cohen JA, Cutter GR, Sørensen PS, Thompson AJ, Wolinsky JS, Balcer LJ, Banwell B, Barkhof $F$ et al: Defining the clinical course of multiple sclerosis: The 2013 revisions. Neurology 2014, 83(3):278-286.

4. Milo R, Kahana E: Multiple sclerosis: geoepidemiology, genetics and the environment. Autoimmunity reviews 2010, 9(5):A387-394.

5. A visual look at new worldwide multiple sclerosis prevalence data [https://www.vitamindcouncil.org/a-visual-look-at-new-worldwide-multiple-sclerosis-prevalencedata/]

6. Thompson AJ, Baranzini SE, Geurts J, Hemmer B, Ciccarelli O: Multiple sclerosis. The Lancet 2018, 391(10130):1622-1636.

7. Etemadifar M, Sajjadi S, Nasr Z, Firoozeei TS, Abtahi SH, Akbari M, Fereidan-Esfahani M: Epidemiology of multiple sclerosis in Iran: a systematic review. European neurology 2013, 70(56):356-363.

8. Izadi S, Nikseresht AR, Poursadeghfard M, Borhanihaghighi A, Heydari ST: Prevalence and Incidence of Multiple Sclerosis in Fars Province, Southern Iran. Iranian Journal of Medical Sciences 2015, 40(5):390-395.

9. Pekmezovic T, Drulovic J, Milenkovic M, Jarebinski M, Stojsavljevic N, Mesaros S, Kisic D, Kostic J: Lifestyle Factors and Multiple Sclerosis: A Case-Control Study in Belgrade. Neuroepidemiology 2006, 27(4):212-216.

10. Hedström A, Hillert J, Olsson T, Alfredsson L: Alcohol as a modifiable lifestyle factor affecting multiple sclerosis risk. JAMA neurology 2014, 71(3):300-305. 
11. Ascherio A, Munger KL: Environmental risk factors for multiple sclerosis. Part I: the role of infection. Ann Neurol 2007, 61(4):288-299.

12. Browne P, Chandraratna D, Angood C, Tremlett H, Baker C, Taylor BV, Thompson AJ: Atlas of Multiple Sclerosis 2013: A growing global problem with widespread inequity. Neurology 2014, 83(11):10221024.

13. Dumas M, Jauberteau-Marchan MO: The protective role of Langerhans' cells and sunlight in multiple sclerosis. Medical hypotheses 2000, 55(6):517-520.

14. Ebers GC: Environmental factors and multiple sclerosis. The Lancet Neurology 2008, 7(3):268-277.

15. Giovannoni G, Ebers G: Multiple sclerosis: the environment and causation. Current opinion in neurology 2007, 20(3):261-268.

16. Hedstrom AK, Hillert J, Olsson T, Alfredsson L: Smoking and multiple sclerosis susceptibility. European journal of epidemiology 2013, 28(11):867-874.

17. Hoseinzadeh E, Taha P, Wei C, Godini H, Ashraf GM, Taghavi M, Miri M: The impact of air pollutants, UV exposure and geographic location on vitamin D deficiency. Food and Chemical Toxicology 2018, 113:241-254.

18. Koch-Henriksen N, Stenager E, Laursen B: The use of epidemiological multiple sclerosis registers in research: the Danish MS Registry. Acta neurologica Scandinavica Supplementum 2012(195):7-12.

19. Kurtzke JF: Epidemiologic evidence for multiple sclerosis as an infection. Clinical microbiology reviews 1993, 6(4):382-427.

20. Orton SM, Herrera BM, Yee IM, Valdar W, Ramagopalan SV, Sadovnick AD, Ebers GC: Sex ratio of multiple sclerosis in Canada: a longitudinal study. The Lancet Neurology 2006, 5(11):932-936.

21. Pivot D, Debouverie M, Grzebyk M, Brassat D, Clanet M, Clavelou P, Confavreux C, Edan G, Leray E, Moreau T et al: Geographical Heterogeneity of Multiple Sclerosis Prevalence in France. PLOS ONE 2016, 11(12):e0167556.

22. Anderson C, Ryan LM: A Comparison of Spatio-Temporal Disease Mapping Approaches Including an Application to Ischaemic Heart Disease in New South Wales, Australia. International Journal of Environmental Research and Public Health 2017, 14(2):146.

23. Statistical Center of Iran. Iran National Census, Tehran, Statistical Center of Iran 2016.

24. Polman CH, Reingold SC, Banwell B, Clanet M, Cohen JA, Filippi M, Fujihara K, Havrdova E, Hutchinson M, Kappos L et al: Diagnostic criteria for multiple sclerosis: 2010 Revisions to the McDonald criteria. Annals of Neurology 2011, 69(2):292-302.

25. David Spiegelhalter, Andrew Thomas, Nicky Best, Lunn D: OpenBUGS. 2014.

26. ESRI: ArcGIS Desktop: Release 10. Redlands, CA: Environmental Systems Research Institute. 2011.

27. Sharafi Z, Asmarian N, Hoorang S, Mousavi A: Bayesian spatio-temporal analysis of stomach cancer incidence in Iran, 2003-2010. Stochastic Environmental Research and Risk Assessment 2018.

28. Ebrahimipour M, Budke CM, Najjari M, Cassini R, Asmarian N: Bayesian spatial analysis of the surgical incidence rate of human cystic echinococcosis in north-eastern Iran. Acta tropica 2016, 
163:80-86.

29. Alharbi FM: Update in vitamin D and multiple sclerosis. Neurosciences 2015, 20(4):329-335.

30. Fitzgerald KC, Munger KL, Kochert K, Arnason BG, Comi G, Cook S, Goodin DS, Filippi M, Hartung HP, Jeffery DR et al: Association of Vitamin D Levels With Multiple Sclerosis Activity and Progression in Patients Receiving Interferon Beta-1b. JAMA neurology 2015, 72(12):1458-1465.

31. Wawrzyniak S, Mikołajewska E, Kuczko-Piekarska E, Niezgodzińska-Maciejek A, Goch A: Association of vitamin D status and clinical and radiological outcomes in a treated MS population in Poland. Brain and Behavior 2017, 7(2):e00609.

32. O'Connor P: Multiple Sclerosis The Facts You Need, 5 edn.

33. Saei M, Holakouie-Naieni K, Mostafavi E, Sahraian MA, Mahmoodi M, Mansournia MA, Hosseini A: Spatial Analysis of Multiple Sclerosis Disease in Tehran Metropolitan Zone, Iran, 2001-2012. Iranian Journal of Public Health 2014, 43(5):621-629.

34. Goulden R, Ibrahim T, Wolfson C: Is high socioeconomic status a risk factor for multiple sclerosis? A systematic review. European Journal of Neurology 2015, 22(6):899-911.

35. D'Hooghe M B, Haentjens P, Nagels G, Garmyn M, De Keyser J: Sunlight exposure and sun sensitivity associated with disability progression in multiple sclerosis. Multiple sclerosis (Houndmills, Basingstoke, England) 2012, 18(4):451-459.

36. Hedstrom AK, Sundqvist E, Baarnhielm M, Nordin N, Hillert J, Kockum I, Olsson T, Alfredsson L: Smoking and two human leukocyte antigen genes interact to increase the risk for multiple sclerosis. Brain : a journal of neurology 2011, 134(Pt 3):653-664.

37. Hernan MA, Olek MJ, Ascherio A: Cigarette smoking and incidence of multiple sclerosis. American journal of epidemiology 2001, 154(1):69-74.

38. Wingerchuk DM: Smoking: effects on multiple sclerosis susceptibility and disease progression. Therapeutic advances in neurological disorders 2012, 5(1):13-22.

39. Hedstrom AK, Bomfim IL, Barcellos LF, Briggs F, Schaefer C, Kockum I, Olsson T, Alfredsson L: Interaction between passive smoking and two HLA genes with regard to multiple sclerosis risk. International journal of epidemiology 2014, 43(6):1791-1798.

40. Munger KL, Bentzen J, Laursen B, Stenager E, Koch-Henriksen N, Sorensen TI, Baker JL: Childhood body mass index and multiple sclerosis risk: a long-term cohort study. Multiple sclerosis (Houndmills, Basingstoke, England) 2013, 19(10):1323-1329.

41. Harroud A, Morris JA, Manousaki D, Forgetta V, Mitchell R, Smith GD, Sawcer S, Richards JB: Distinct Effects of Obesity and Vitamin D on Risk of Multiple Sclerosis: A Mendelian Randomization Study (P2.351). Neurology 2018, 90(15 Supplement).

42. Hedstrom AK, Olsson T, Alfredsson L: High body mass index before age 20 is associated with increased risk for multiple sclerosis in both men and women. Multiple sclerosis (Houndmills, Basingstoke, England) 2012, 18(9):1334-1336. 
43. Carle A, Pedersen IB, Knudsen N, Perrild H, Ovesen L, Rasmussen LB, Jorgensen T, Laurberg P: Moderate alcohol consumption may protect against overt autoimmune hypothyroidism: a population-based case-control study. European journal of endocrinology 2012, 167(4):483-490.

44. Bai L, Burnett RT, Kwong JC, Hystad P, van Donkelaar A, Brook JR, Tu K, Copes R, Goldberg MS, Martin RV et al: Long-term exposure to air pollution and the incidence of multiple sclerosis: A population-based cohort study. Environmental Research 2018, 166:437-443.

45. Esmaeil Mousavi S, Heydarpour P, Reis J, Amiri M, Sahraian MA: Multiple sclerosis and air pollution exposure: Mechanisms toward brain autoimmunity. Medical hypotheses 2017, 100:23-30.

46. Calderon-Garciduenas L, Leray E, Heydarpour P, Torres-Jardon R, Reis J: Air pollution, a rising environmental risk factor for cognition, neuroinflammation and neurodegeneration: The clinical impact on children and beyond. Revue neurologique 2016, 172(1):69-80.

47. Roux J, Bard D, Le Pabic E, Segala C, Reis J, Ongagna JC, de Seze J, Leray E: Air pollution by particulate matter PM10 may trigger multiple sclerosis relapses. Environ Res 2017, 156:404-410.

48. Landtblom AM, Wastenson M, Ahmadi A, Söderkvist P: Multiple sclerosis and exposure toorganic solvents, investigated by genetic polymorphisms of theGSTM1 and CYP2D6 enzyme systems. Neurological Sciences 2003, 24(4):248-251.

\section{Figures}

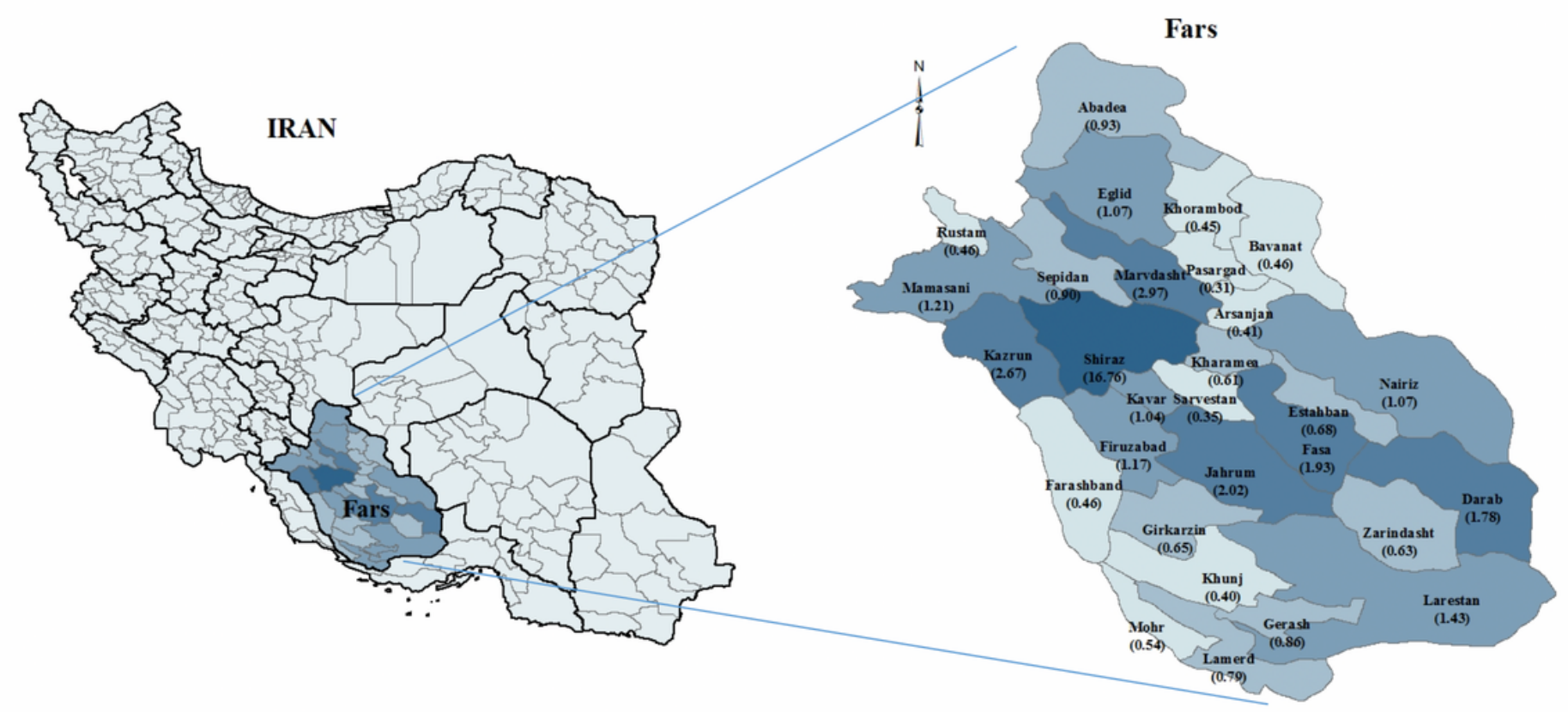

\section{Figure 1}

geographical location of Fars province and its counties (created using ArcGIS Desktop: Release 10.1, https://www.esri.com/en-us/arcgis/about-arcgis/overview) 
A

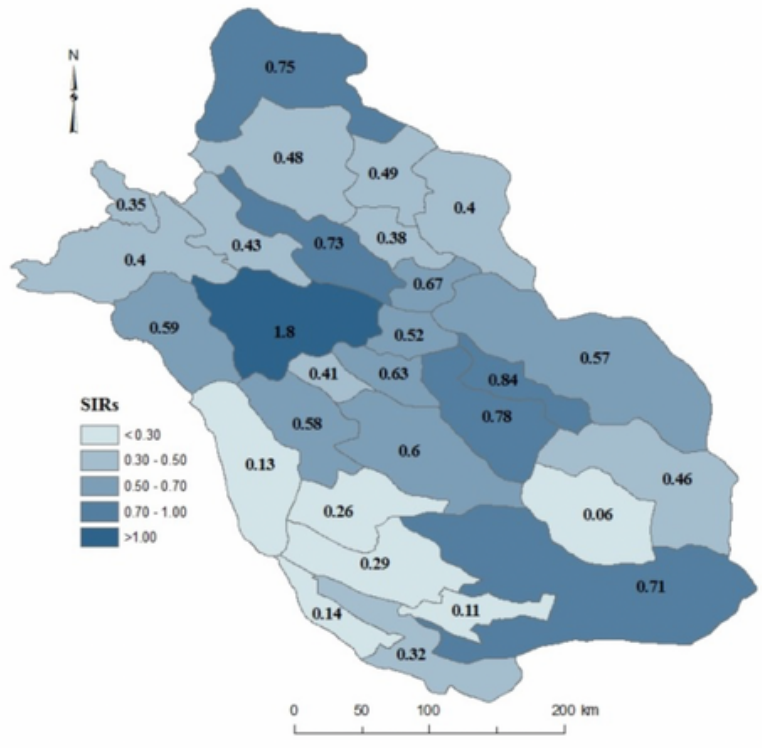

$\mathrm{C}$

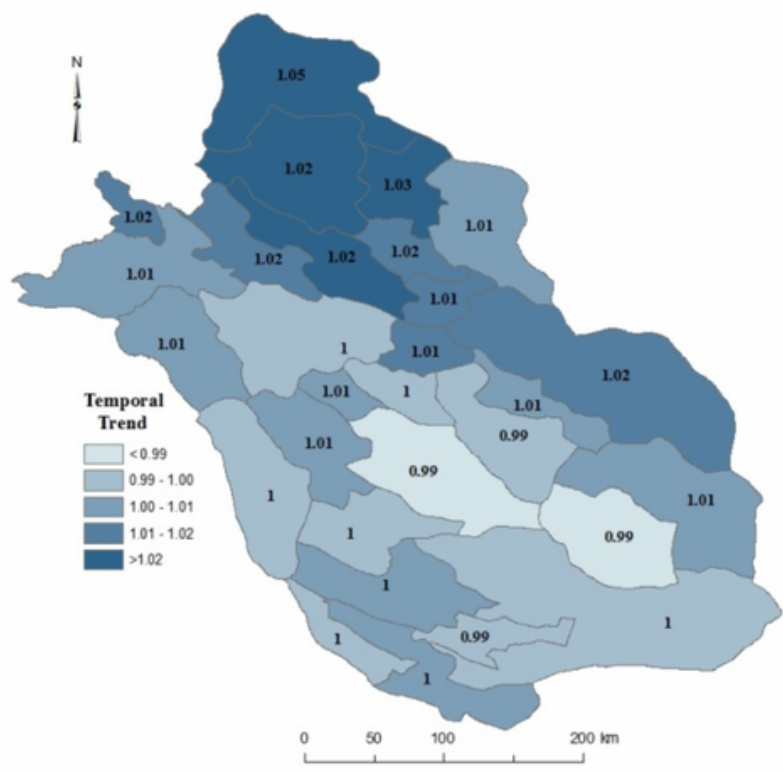

B

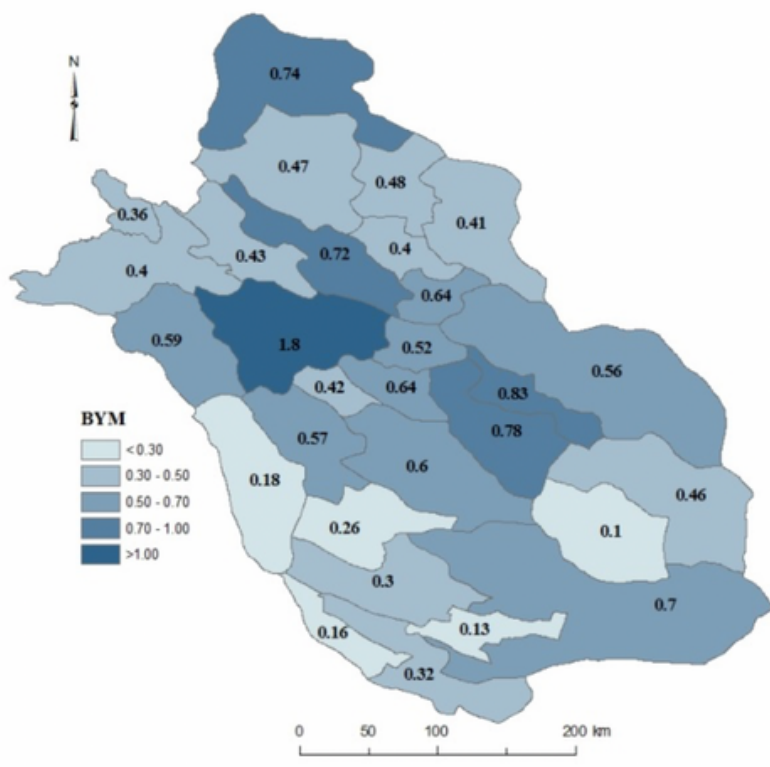

$\mathrm{D}$

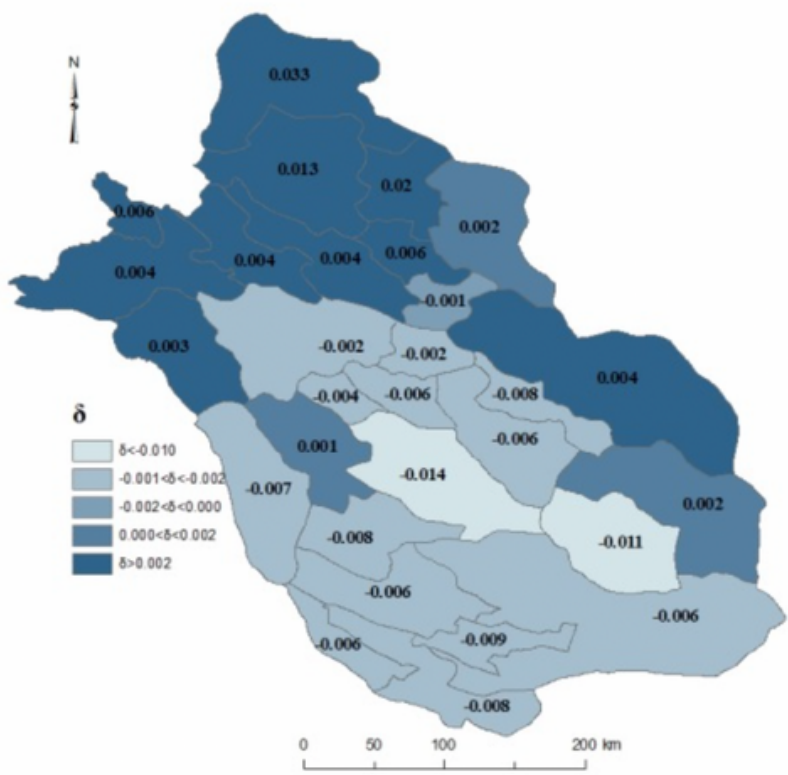

\section{Figure 2}

MS incidence rate across the 29 counties of Fars province with classic SIR (A), BYM model (B) spatiotemporal model (C), and posterior estimate value of $\delta \_i(D)$ (created using ArcGIS Desktop: Release 10.1, https://www.esri.com/en-us/arcgis/about-arcgis/overview) 